\title{
Haematological factors associated with proliferative retinopathy in sickle cell-haemoglobin $\mathrm{C}$ disease
}

\author{
R. J. HAYES, ${ }^{1}$ P. I. CONDON ${ }^{2}$ AND G. R. SERJEANT ${ }^{2}$
}

From the ${ }^{2}$ Medical Research Council Laboratories (Jamaica), University of the West Indies, Mona, Kingston 7, Jamaica, WI, and the 'Tropical Epidemiology Unit, London School of Hygiene and Tropical Medicine, Keppel Street, London WC1E 7HT.

SUMMARY In a selected sample of patients with sickle cell-haemoglobin C (SC) disease, proliferative retinopathy (PSR) occurred in 90/243 (37\%) patients, developed most frequently between the ages of 20 and 30 years, and affected $68 \%$ patients aged 45 years or over. Comparison of haematological indices in patients with and without PSR, after age-related effects were allowed for, indicated significant relationships with high mean cell volume in males and with low fetal haemoglobin in both sexes. A highly significant relationship with total haemoglobin level in males (as previously reported in SS disease) was shown in SC disease to be entirely secondary to a strong age-related trend in haemoglobin level.

Small vessel occlusion in the peripheral retina in sickle cell disease initiates a sequence of vascular events which may culminate in proliferative sickle retinopathy (PSR). This complication occurs in all genotypes of sickle cell disease but is most common in sickle cell-haemoglobin C (SC) disease. Prospective studies of sickle cell eye disease in Jamaica had identified 90 patients with SC disease and PSR by July 1978. In the present study the haematological indices of these patients were compared with those of SC patients without PSR in an attempt to identify factors associated with the development of the complication.

\section{Patients and methods}

The sickle cell clinic at the University Hospital of the West Indies in Kingston, Jamaica, has approximately 400 patients with SC disease in attendance. In November 1970 ocular examinations were performed on 70 patients. ${ }^{1}$ This initial group was not selected because of ocular symptoms and could probably be regarded as a representative sample of clinic patients with SC disease. Since then many additional patients have been examined, some after presenting with

Correspondence to Dr Graham R. Serjeant, Medical Research Council Laboratories, University of the West Indies, Mona, Kingston 7, Jamaica, WI. ocular symptoms, while others were screened during routine visits to the clinic.

By July 1978 ocular examinations had been performed in a total of 243 SC patients (115 males, 128 females) with ages ranging from 5 to 70 years, and these patients constituted the study group. Many have been given follow-up examinations, the number of ocular examinations per patient varying between 1 and 8. Inferences about the prevalence of PSR in the clinic population were complicated by symptomatic presentation and other selection biases in this sample, but such biases should not invalidate a comparison of haematological indices in patients with and without PSR in a search for factors relevant to the development of the condition.

Techniques of ocular examination have been described previously, as have the criteria for the diagnosis of SC disease. ${ }^{12}$ Total haemoglobin $(\mathrm{Hb})$, red cell count (RBC), and mean cell volume (MCV) were measured in an electronic cell counter (Coulter ZB1 6, Coulter Electronics, Hialeah, Florida) calibrated with a commercial control (4C Control, Coulter Electronics). Packed cell volume (PCV) was measured as the microhaematocrit and the mean cell haemoglobin concentration (MCHC) calculated from the $\mathrm{Hb}$ and PCV. Platelets were counted in an electronic counter (Coulter Thrombocounter, Coulter Electronics). Fetal haemoglobin (HbF) was measured 
Table 1 Sample prevalence of PSR by sex and age group at first ocular examination

\begin{tabular}{|c|c|c|c|c|}
\hline \multirow{2}{*}{$\begin{array}{l}\text { Age at first } \\
\text { ocular } \\
\text { examination } \\
\text { (vears) }\end{array}$} & \multicolumn{2}{|l|}{ Males } & \multicolumn{2}{|l|}{ Females } \\
\hline & $\begin{array}{l}\text { Number } \\
\text { examined }\end{array}$ & $\begin{array}{l}\text { Number } \\
\text { with PSR }\end{array}$ & $\begin{array}{l}\text { Number } \\
\text { examined }\end{array}$ & $\begin{array}{l}\text { Number } \\
\text { with PSR }\end{array}$ \\
\hline $0-14$ & 34 & $1(3 \%)$ & 37 & $2(5 \%)$ \\
\hline $15-24$ & 31 & $11(35 \%)$ & 48 & $3(6 \%)$ \\
\hline $25-34$ & 25 & $17(68 \%)$ & 22 & $8(36 \%)$ \\
\hline $35-44$ & 14 & $8(57 \%)$ & 13 & $5(38 \%)$ \\
\hline $45-$ & 11 & $8(73 \%)$ & 8 & $5(63 \%)$ \\
\hline
\end{tabular}

Note: 22 patients developed PSR at later examinations.

by the alkali denaturation method of Betke et al., ${ }^{3}$ total bilirubin by the method of Lathe and Ruthven, ${ }^{4}$ and serum iron by the method of Beale et al. ${ }^{5}$ Haematological analyses were based on mean steady-state values of $\mathrm{Hb}, \mathrm{MCHC}, \mathrm{MCV}, \mathrm{HbF}$, reticulocytes, platelets, total bilirubin, and serum iron. Statistical inference is improved if variables can be assumed approximately normal, and as the distributions of $\mathrm{HbF}$ and reticulocytes were positively skewed the transformed values $\log _{e}(\% \mathrm{HbF}+4)$ and $\log _{e}(\%$ reticulocytes +1 ) were used to obtain more nearly symmetrical distributions for these variables.

In the statistical analysis the 'age' of each patient was defined, for reasons described previously, ${ }^{6}$ as that at which he or she most recently attended the clinic.

\section{Results}

\section{PREVALENCE AND INCIDENCE}

Lesions of PSR, either leaking or occluded, were detected in 53/115 (46\%) males and in 37/128 (29\%) females in this sample. The proportion of patients with PSR increased with age (Table 1), 9/10 patients aged 50 years or over having PSR at their first ocular examination. There was a tendency for lesions to be more common in males, a Mantel-Haenszel test yielding a $\chi^{2}$ (with $\left.1 \mathrm{Df}\right)$ of $10 \cdot 8(\mathrm{p} \simeq 0 \cdot 001)$. These
Table 2 Incidence rates for the initial development of PSR

\begin{tabular}{llll}
\hline $\begin{array}{l}\text { Age group } \\
\text { (vears) }\end{array}$ & $\begin{array}{l}\text { Patients } \\
\text { developing } \\
\text { PSR }\end{array}$ & $\begin{array}{l}\text { Patient-years } \\
\text { at risk }\end{array}$ & $\begin{array}{l}\text { Incidence rate } \\
\text { per } 100 \\
\text { patient-years } \\
\text { at risk }\end{array}$ \\
\hline $0-9$ & 0 & 44 & 0 \\
$10-14$ & 2 & 90 & 2 \\
$15-19$ & 5 & 103 & 5 \\
$20-24$ & 9 & 56 & 16 \\
$25-34$ & 4 & 31 & 13 \\
$35-$ & 2 & 46 & 4 \\
\hline
\end{tabular}

findings require cautious interpretation because of the selection biases referred to above.

Of the 90 patients with PSR 68 had already developed lesions prior to their first ocular examination, while onset was recorded prospectively in the remaining 22 patients. Data from patients who were followed up prospectively allowed the calculation of approximate incidence rates for the onset of PSR (Table 2). Although these rates will again be subject to biases in patient selection, they suggest that patients aged $20-30$ are at particuarly high risk of developing PSR.

\section{HAEMATOLOGICAL COMPARISONS}

Means and standard deviations of haematological indices in patients with and without evidence of PSR are shown in Tables 3 and 4 . Several patients were found to have extreme values of one or more parameters, and in each of the analyses that follow, the effects of omitting these outliers were examined to ensure that inferences were not unduly influenced by these values.

Indices in patients with and without PSR were compared initially by Student's $t$ test, unless significantly differing sample variances indicated the use of Welch's test. ${ }^{7}$ In males with PSR the mean levels of $\mathrm{Hb}$ and MCV were significantly higher $(\mathrm{p}<0.001)$, HbF significantly lower $(p \simeq 0 \cdot 01)$, and MCHC signifi-

Table 3 Comparison of haematological indices in male patients with and without PSR

\begin{tabular}{|c|c|c|c|c|c|c|c|c|}
\hline \multirow[t]{2}{*}{ Variable } & \multicolumn{3}{|c|}{ With PSR } & \multicolumn{3}{|c|}{ Without PSR } & \multirow[t]{2}{*}{$t$} & \multirow[t]{2}{*}{ Significance } \\
\hline & $n$ & Mean & $S D$ & $n$ & Mean & $S D$ & & \\
\hline Age (years) & 53 & $32 \cdot 4$ & 13.9 & 62 & $18 \cdot 6$ & $11 \cdot 5$ & - & - \\
\hline $\mathrm{HbF}\left(\log _{e}(\% \mathrm{~F}+4)\right)$ & 48 & $1 \cdot 58^{\prime}$ & $0 \cdot 13$ & 54 & $1 \cdot 68^{2}$ & $0 \cdot 26$ & $-2 \cdot(6)^{*}$ & $p \simeq() \cdot() 1$ \\
\hline $\mathrm{Hb}(\mathrm{g} / \mathrm{dl})$ & 52 & $12 \cdot 9$ & $1 \cdot 6$ & 61 & $11 \cdot 7$ & 1.5 & $4 \cdot 17$ & $p<0) \cdot(x) 1$ \\
\hline $\mathrm{MCHC}(\mathrm{g} / \mathrm{dl})$ & 52 & $35 \cdot 4$ & $1 \cdot 2$ & 61 & $34 \cdot 9$ & 1.2 & $2 \cdot 35$ & $p<0) \cdot 05$ \\
\hline $\operatorname{MCV}(f)$ & 52 & $82 \cdot 9$ & $6 \cdot 0$ & 59 & $78 \cdot 6$ & $6 \cdot 1$ & $3 \cdot 68$ & $p<0) \cdot(001$ \\
\hline Retics. $\left(\log _{e}(\%\right.$ retics. +1$\left.)\right)$ & 52 & $1 \cdot 41^{3}$ & $0 \cdot 24$ & 60 & $1 \cdot 46^{4}$ & $0 \cdot 34$ & $-0 \cdot 81^{*}$ & NS \\
\hline Platelets $\left(\times 10^{9} / 1\right)$ & 33 & 285 & 147 & 42 & 321 & 138 & $-1 \cdot(1)$ & NS \\
\hline Tot. bilirubin (mg/dl) & 49 & $1 \cdot 52$ & 0.99 & 55 & $1 \cdot 45$ & 0.96 & $0 \cdot 39$ & NS \\
\hline Serum Fe $(\mu \mathrm{g} / \mathrm{dl})$ & 50 & $79 \cdot 8$ & $18 \cdot 7$ & 58 & $84 \cdot 2$ & $28 \cdot 4$ & $-0.96^{*}$ & NS \\
\hline
\end{tabular}

Transformed variables re-expressed as $\%:$ (1) $0 \cdot 8$, (2) $1 \cdot 4$, (3) $3 \cdot 1$, (4) $3 \cdot 3$.

*Welch's test statistic (see text). 
Table 4 Comparison of haematological indices in female patients with and without PSR

\begin{tabular}{|c|c|c|c|c|c|c|c|c|}
\hline \multirow[t]{2}{*}{ Variable } & \multicolumn{3}{|c|}{ With PSR } & \multicolumn{3}{|c|}{ Without PSR } & \multirow[t]{2}{*}{$t$} & \multirow[t]{2}{*}{ Significance } \\
\hline & $n$ & Mean & $S D$ & $n$ & Mean & $S D$ & & \\
\hline Age (years) & 37 & $31 \cdot 5$ & $13 \cdot 3$ & 91 & $21 \cdot 1$ & $10 \cdot 1$ & - & - \\
\hline $\mathrm{HbF}\left(\log _{e}(\% \mathrm{~F}+4)\right)$ & 33 & $1 \cdot 59^{1}$ & $0 \cdot 12$ & 77 & $1 \cdot 65^{2}$ & $0 \cdot 19$ & $-2 \cdot 26^{*}$ & $p<0) \cdot(05$ \\
\hline $\mathrm{Hb}(\mathrm{g} / \mathrm{dl})$ & 37 & $11 \cdot 5$ & $1 \cdot 0$ & 90 & $11 \cdot 1$ & $1 \cdot 3$ & $1 \cdot 65$ & NS \\
\hline $\operatorname{MCHC}(g / d l)$ & 37 & $34 \cdot 8$ & $1 \cdot 1$ & 89 & $34 \cdot 9$ & $1 \cdot 2$ & -0.73 & NS \\
\hline $\operatorname{MCV}(f)$ & 37 & $80 \cdot 8$ & $6 \cdot 1$ & 87 & $78 \cdot 7$ & $5 \cdot 9$ & 1.76 & NS \\
\hline Retics. $\left(\log _{\mathrm{e}}(\%\right.$ retics. +1$\left.)\right)$ & 37 & $1 \cdot 48^{3}$ & $0 \cdot 30$ & 87 & $1 \cdot 44^{4}$ & $0 \cdot 30$ & 0.74 & NS \\
\hline Platelets $\left(\times 10^{\circ} / 1\right)$ & 30 & 276 & 132 & 62 & 289 & 126 & -0.47 & NS \\
\hline Tot. bilirubin (mg/dl) & 37 & $1 \cdot 22$ & 0.53 & 83 & $1 \cdot 13$ & 0.65 & $0 \cdot 81$ & NS \\
\hline Serum Fe $(\mu \mathrm{g} / \mathrm{dl})$ & 36 & $78 \cdot 3$ & $27 \cdot 6$ & 85 & $75 \cdot 7$ & $20 \cdot 1$ & $0.51^{*}$ & NS \\
\hline
\end{tabular}

Transformed variables re-expressed as \%: (1) $0 \cdot 9$, (2) $1 \cdot 2$, (3) $3 \cdot 4$, (4) $3 \cdot 2$.

*Welch's test statistic (see text).

cantly higher $(p<0 \cdot 05)$ than in males without PSR. In females the differences in $\mathrm{Hb}, \mathrm{MCV}$, and $\mathrm{HbF}$ were in the same direction as for males, but only the difference in $\mathrm{HbF}$ reached statistical significance $(\mathrm{p}<0.05)$.

In the course of this study, it has become clear that some of the above findings may be misleading. There is some evidence in SC patients of strong age-related trends in certain parameters, including both $\mathrm{Hb}$ and $\mathrm{MCV}$. As a result an observation that a parameter is significantly higher in patients with PSR may reflect the age distribution of these patients. In order to allow for age-related effects, and also for correlations between haematological indices, the data were further explored by means of multiple logistic regression analysis. ${ }^{8}$ With this technique it was possible to examine whether PSR status appeared to be influenced jointly by a combination of variables, appropriate age and sex terms being incorporated in the analysis. Preliminary analyses indicated that platelets were unrelated to PSR, and since platelet levels were unavailable for many patients they were excluded from this analysis. The youngest patient with PSR in this sample was aged 12, and the regression analysis was therefore restricted to patients aged 12 or over-that is, the group thought to be at risk. There were 171 patients in this age group with steady-state values for all indices (excluding platelets).

In males the analysis confirmed the association of high MCV and low HbF with PSR but the effect of total $\mathrm{Hb}$ was no longer significant after allowing for age. In females low $\mathrm{HbF}$ levels were again associated with PSR, but no other parameter significantly improved the fit of the regression model.

These findings are illustrated in Figures 1-4. Fetal haemoglobin levels were generally between 0 and $2 \%$, but a few patients had higher values of up to $10 \%$ (Figs. 1-2). Only 1 of the patients with HbF over $3 \%$ had PSR, even though 7 of these were over 20 years old. When patients with values over $3 \%$ were excluded from the analysis, the effect of $\mathrm{HbF}$ was no longer statistically significant. Thus the apparent association of this parameter with PSR mav be explained by a protective effect in the few patients with unusually high $\mathrm{HbF}$ levels.

In males $\mathrm{Hb}$ levels rose steeply with increasing age
Fig. 1 Relationship between $\mathrm{HbF}$ levels and age in male patients with (O) and without (D) PSR.

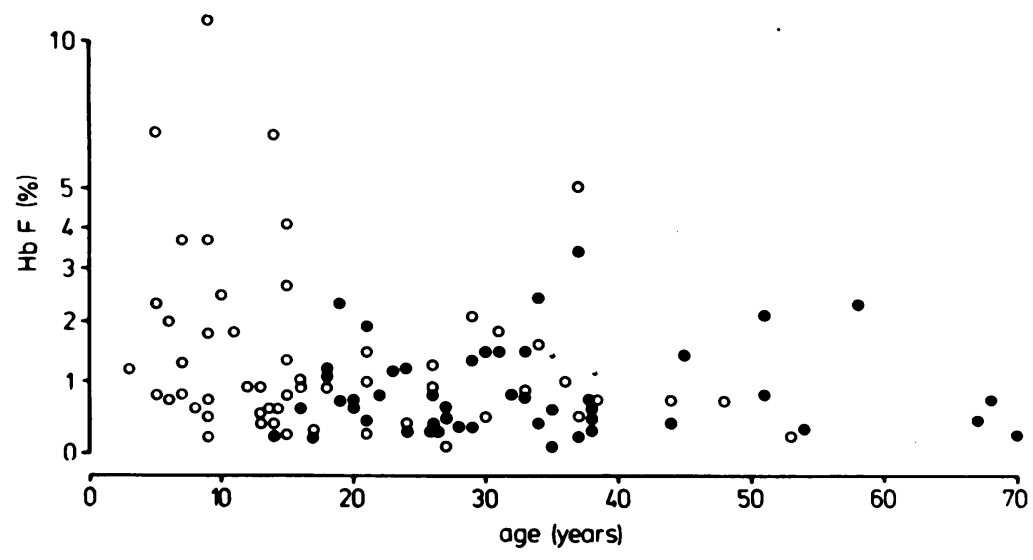




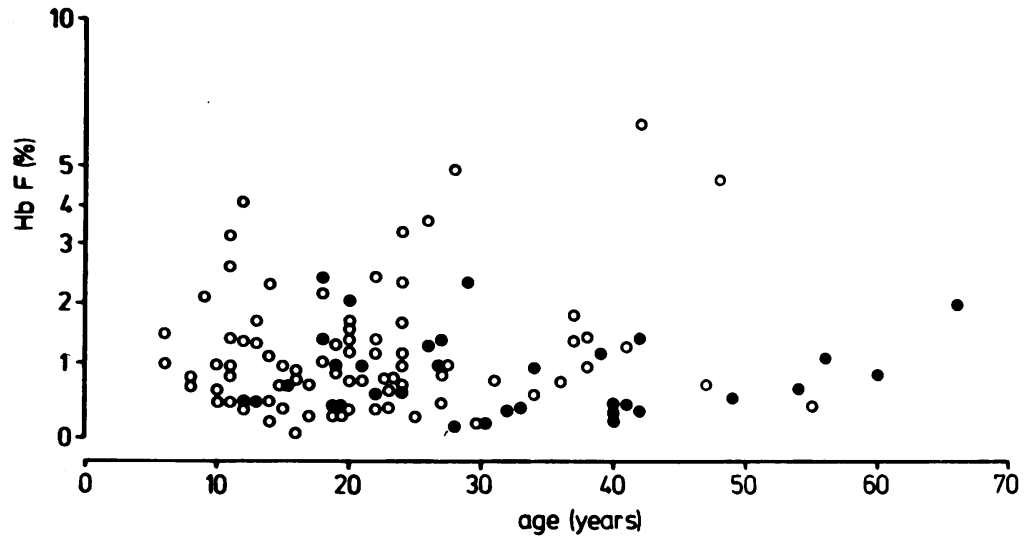

Fig. 2 Relationship between $\mathrm{HbF}$ levels and age in female patients with (O) and without (O) PSR.

up to 40 years (Fig. 3) and appeared to decline thereafter. Because of this age relationship, and because patients with PSR were older on average, the PSR group appeared to have raised $\mathrm{Hb}$ levels. However, there was no consistent tendency for patients with PSR to have higher $\mathrm{Hb}$ levels than other patients of the same age.

Average MCV levels also increased with age (Fig. 4), but the age relationship appeared weaker, and within each age group MCV levels of PSR patients did appear higher on average than those of patients without PSR. However, there was substantial variation in the MCV levels of patients with PSR, several having average or below average MCV.

\section{AGE/SEX MATCHED COMPARISONS}

In an attempt to gain further insight into the relationships suggested above PSR patients were, wherever possible, matched by age and sex with control patients without PSR, giving 47 matched pairs (22 male, 25 female pairs). Haematological comparisons were made by the $t$ test for matched pairs, and the results are summarised in Table 5.

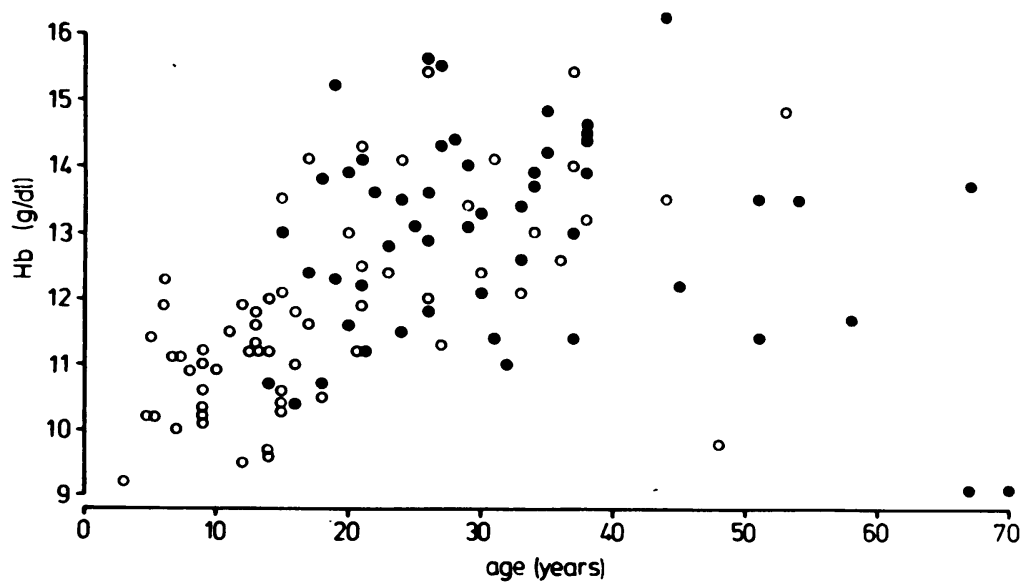

\section{Discussion}

The findings agree broadly with those of the regression analyses. There were 4 patients ( 1 male, 3 females) in this group with $\mathrm{HbF}$ levels above $3 \%$, all of whom were controls. The overall $t$ value for $\mathrm{HbF}$ was statistically significant $(p<0 \cdot 05)$, but became nonsignificant if these 4 extreme values were omitted from the analysis. In both sexes average MCV levels were higher in patients with PSR, and overall the difference just reached statistical significance $(\mathrm{p}<0.05)$. There was no significant difference in $\mathrm{Hb}$ levels between patients with and without PSR in either sex. In females reticulocyte levels appeared to be slightly higher in patients with PSR.

The most significant difference in this subgroup of patients related to $\mathrm{MCHC}$ levels in males. In $18 / 22$ matched pairs the MCHC level of the patient with PSR exceeded that of the control, and the $t$ value of 4.44 was highly significant $(p<0 \cdot 001)$. There was no corresponding effect in females, however.

Proliferative retinopathy is a common complication 
Fig. 4 Relationship between $M C V$ and age in male patients with (O) and without (O) PSR.

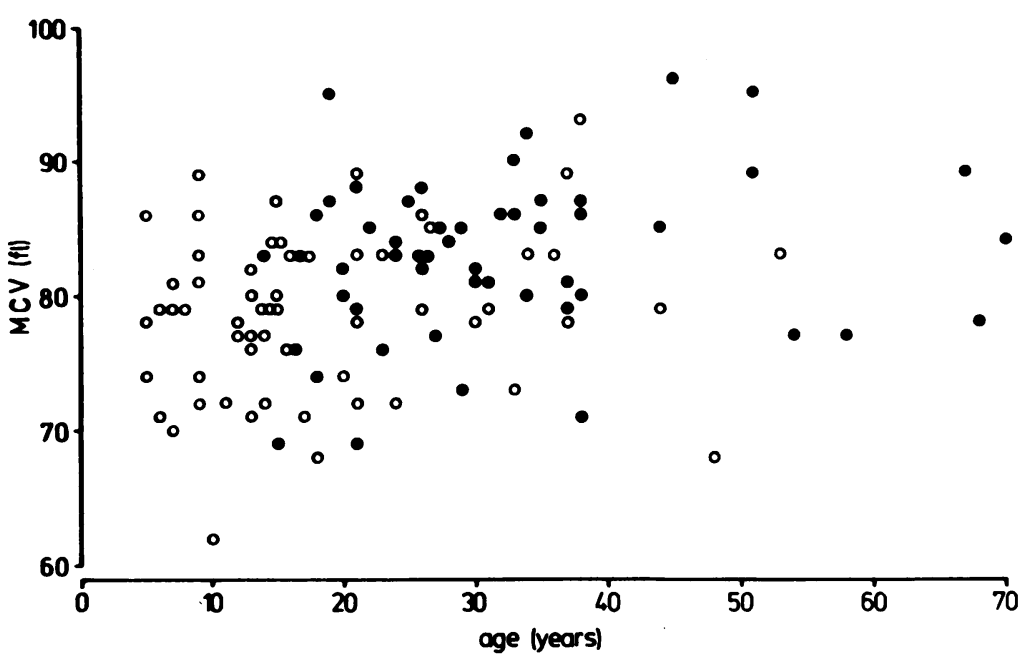

of sickle cell-haemoglobin $\mathrm{C}$ disease. While selection biases in this study may have led to the overestimation of prevalence in younger patients, there was a policy of performing retinal examinations in all available patients over the age of 30 years, and prevalence estimates in these older groups should be fairly reliable. PSR was seen in more than $50 \%$ of patients aged 45 years or over.

At almost all ages PSR was more common in males than females. The difference was quite substantial in the 15-34 year age groups, and it seems unlikely this could be explained in terms of selection effects. The reason for the higher prevalence in males is unclear. The most obvious sex difference in haematological indices is in total haemoglobin, and it was originally thought that PSR might be related to raised haemoglobin levels. This would also help to explain the considerably higher prevalence of PSR in SC disease than in SS disease with its lower levels of haemoglobin. Total haemoglobin is an important determinant of blood viscosity, and, although the effect may be markedly dependent on vessel size, ${ }^{9}$ recent observations suggest the relevance of haemoglobin levels in the normal range to blood flow in the capillary beds. ${ }^{10}$ However, if high haemoglobin levels caused PSR, we would expect to see a relationship between PSR and haemoglobin within SC patients of a given age and sex. Although preliminary analyses in this study suggested a strong association between haemoglobin level and PSR in males with SC disease, subsequent analyses indicated that this association was entirely secondary to the strong age-related trend in haemoglobin level. Within age groups there was no tendency for patients with PSR to have higher haemoglobin levels. A similar study of PSR in SS disease ${ }^{6}$ revealed a strong association with high haemoglobin levels, even after allowing for age-related effects, and the failure to demonstrate a corresponding association in SC disease was surprising.

Of the haematological indices examined in this study only $\mathrm{HbF}$ and $\mathrm{MCV}$ appeared to be associated with PSR in both sexes. High levels of $\mathrm{HbF}$ are well recognised as being associated with clinical mildness in SS disease, but such an effect has not previously been noted in SC disease. Moreover, the elevation of $\mathrm{HbF}$ in SS disease is much more substantial than the

Table 5 Comparison of haematological indices in 47 patients with PSR and age/sex matched controls

\begin{tabular}{|c|c|c|c|c|c|c|c|c|}
\hline \multirow[t]{2}{*}{ Variable } & \multicolumn{3}{|c|}{ Males (22 pairs) } & \multicolumn{3}{|c|}{ Females (25 pairs) } & \multirow{2}{*}{ Overall } & \multirow[t]{2}{*}{ Significance } \\
\hline & $\begin{array}{l}\text { Mean of } \\
\text { patients } \\
\text { with PSR }\end{array}$ & $\begin{array}{l}\text { Mean of } \\
\text { patients } \\
\text { without PSR }\end{array}$ & $\mathbf{t}$ & $\begin{array}{l}\text { Mean of } \\
\text { patients } \\
\text { with PSR }\end{array}$ & $\begin{array}{l}\text { Mean of } \\
\text { patients } \\
\text { without PSR }\end{array}$ & $t$ & & \\
\hline $\mathrm{HbF}\left(\log _{e}(\% \mathrm{HbF}+4)\right)$ & $1 \cdot 55^{\prime}$ & $1 \cdot 59^{2}$ & $-0 \cdot 87$ & $1 \cdot 56^{3}$ & $1 \cdot 66^{4}$ & $-2 \cdot 07$ & $-2 \cdot 19$ & $\mathrm{p}<0.0 .5$ \\
\hline $\mathrm{Hb}(\mathrm{g} / \mathrm{dl})$ & $13 \cdot 1$ & $12 \cdot 9$ & $0 \cdot 74$ & $11 \cdot 5$ & $11 \cdot 3$ & 0.72 & $1 \cdot 04$ & NS \\
\hline $\mathrm{MCHC}(\mathrm{g} / \mathrm{dl})$ & $36 \cdot 0$ & $34 \cdot 7$ & $4 \cdot 44$ & $35 \cdot 0$ & $34 \cdot 9$ & $0 \cdot 26$ & $2 \cdot 68$ & $p=0 \cdot 01$ \\
\hline $\operatorname{MCV}(f)$ & $83 \cdot 7$ & 79.9 & 1.52 & $81 \cdot 0$ & $78 \cdot 8$ & 1.29 & $2 \cdot 01$ & $p=0.05$ \\
\hline Retics. $\left(\log _{e}(\%\right.$ retics. +1$\left.)\right)$ & $1 \cdot 43^{5}$ & $1.49^{6}$ & $-0 \cdot 58$ & $1 \cdot 48^{7}$ & $1 \cdot 31^{8}$ & 1.99 & $0 \cdot 83$ & NS \\
\hline Serum $\mathrm{Fe}(\mu \mathrm{g} / \mathrm{dl})$ & $83 \cdot 0$ & $95 \cdot 6$ & $-1 \cdot 50$ & $76 \cdot 3$ & $72 \cdot 1$ & $0 \cdot 51$ & $-0 \cdot 61$ & NS \\
\hline
\end{tabular}

Transformed variables re-expressed as \%: (1) $0 \cdot 7$, , (2) $0 \cdot 9$, (3) $0 \cdot 8$, (4) $1 \cdot 3$, (5) $3 \cdot 2$, (6) $3 \cdot 5$, (7) $3 \cdot 4$, (8) $2 \cdot 7$. 
modest elevation generally seen in patients with $\mathrm{SC}$ disease. In the present study only $15 / 243$ patients had $\mathrm{HbF}$ levels above $3 \%$, and when this group was excluded from the analysis the relationship of PSR with $\mathrm{HbF}$ was no longer significant. This would be consistent with a protective effect of $\mathrm{HbF}$ in the few SC patients with particularly high levels, but the sample was too small to draw any firm conclusions.

Average MCV levels were higher in patients with PSR in both males and females, even after age was allowed for. However, the association with MCV was weak, and since there were several patients with PSR who had lower than average MCV it is clear that other unrecognised factors must be of importance in the development of PSR.

Another unexplained aspect of PSR in SC disease is the effect of age. Incidence rates estimated from this study suggest that onset is most common in early adult life between the ages of 20 and 30 years. The mechanism whereby this age group is at special risk of developing PSR is unknown.

Difficulties of interpretation arose in this study because the haematology of some patients with PSR may have been recorded many years after the onset of PSR, whereas the haematology immediately prior to onset is presumably more relevant. It is suggested that much could be learnt by prospectively following up a group of SC patients aged 20-30 years who have not yet developed PSR. The present study suggests that many of these patients would develop the complication over a 5-year follow-up period. Comparison of the longitudinal data on those developing and not developing PSR during this period might shed light on the aetiology of this complication.

References

1 Condon PI, Serjeant GR. Ocular findings in hemoglobin SC disease in Jamaica. Am J Ophthalmol 1972; 74: 921-31.

2 Condon PI, Serjeant GR. Ocular findings in homozygous sickle cell disease in Jamaica. Am J Ophthalmol 1972; 73: 533-43.

3 Betke K, Marti HR, Schlicht I. Estimation of small percentages of fetal haemoglobin. Nature 1959; 184: 1877-8.

4 Lathe GH, Ruthven CRJ. Factors affecting the rate of coupling of bilirubin and conjugated bilirubin in the van den Bergh reaction. J Clin Pathol 1958; 11: 155-61.

5 Beale RN, Bostrum JO, Taylor RF. Improved rapid methods for the determination of iron content and binding capacity of serum. J Clin Pathol 1962; 15: 156-60.

6 Hayes RJ, Condon PI, Serjeant GR. Haematological factors associated with proliferative retinopathy in homozygous sickle cell disease. Br J Ophthalmol 1981; 65: 29-35.

7 Pearson ES, Hartley HO, eds. Biometrika Tables for Statisticians. 3rd ed. Cambridge University Press, 1966: 1: 26-7.

8 Nelder JA, Wedderburn RWM. Generalised linear models. $J R$ Statist Soc (A) 1972; 135: 370-84.

9 Jay AWL, Rowlands S, Skibo L. The resistance to blood flow in the capillaries. Can J Physiol Pharmacol 1972; 50: 1007-13.

10 Thomas DJ, DuBoulay GH, Marshall J, et al. Effect of haematocrit on cerebral blood flow in man. Lancet 1977; ii: 941-3. 